\title{
A study of the effect of high concentrations of fluoride on the reproductive organs of male rabbits, using light and scanning electron microscopy
}

\author{
A. K. Susheela and A. Kumar \\ Fluoride and Fluorosis Research Laboratories, Department of Anatomy, All India Institute of \\ Medical Sciences, New Delhi-110 029, India
}

\begin{abstract}
Summary. Fluoride was orally administered to rabbits at $10 \mathrm{mg} \mathrm{NaF} / \mathrm{kg}$ body weight for 18 or 29 months. The animals were then killed and the structure of the testis, epididymis and vas deferens studied under light and scanning electron microscopes. In animals treated for 29 months, the spermatogenic cells in the seminiferous tubules were disrupted, degenerated and devoid of spermatozoa. In animals treated for 18 or 29 months, loss of cilia on the epithelial cells lining the lumen of the ductuli efferentes of the caput epididymidis and of stereocilia on the epithelial cells lining the lumen of the vas deferens was observed. In some regions of the epithelial lining of the lumen of the ductuli efferentes and vas deferens, the boundaries of the cells were not clear and appeared to be peeled off. Mucus droplets were abundant in the vas deferens of control animals, but absent in both the treated groups. Spermatogenesis ceased only in animals treated for 29 months. The difference in the structural changes observed in the testes of the 2 treated groups may have been due to the blood-testis barrier. It is concluded that ingestion of high concentrations of fluoride has harmful effects on the male reproductive system.
\end{abstract}

Keyrords: fluoride toxicity; spermatogenesis; ductuli efferentes; rabbit

\section{Introduction}

There are few data on the effects of fluoride on the male reproductive system, but a study in male mice ( $\mathrm{Li}$ et al., 1987) showed that fluoride does not have adverse effects on spermatogenesis or sperm morphology, supporting the view that fluoride has no adverse mutagenic effects. However, Vogel (1973) reported a slight decrease in fertility from exposure of mature spermatozoa of Drosophila melanogaster to sodium fluoride. Mukherjee \& Sobels (1968) showed that exposure of Drosophila to sodium fluoride before $\mathrm{X}$-irradiation, led to an increase in radiation-induced recessive lethals in spermatozoa. The authors interpreted the results as an outcome of the inhibition by fluoride of a repair process energized by way of the glycolytic pathway. Studies conducted nearly 50 years ago showed a positive correlation between infertility and fluoride toxicity (Schulz \& Lamb, 1925; Udall \& Kellers, 1952). Tokar \& Savchenko (1977) reported a reduced amount of testosterone and increased concentrations of follicle-stimulating hormone (FSH) in patients with fluorosis; blood concentration of luteinizing hormone was greater than normal in patients who had received prolonged exposure to fluoride. A lack of maturation, differentiation of spermatocytes and loss of spermatogenesis in mice given drinking water containing fluoride have also been reported (Kaur \& Singh, 1980). However, oral administration of sodium fluoride ( $84 \mathrm{mg} / \mathrm{kg}$ body weight) to adult male rats does not induce DNA damage in testicular cells when measured by alkaline elution (Skare et al., 1986). Messer et al. (1973) reported impaired reproduction in mice fed 100 and 200 p.p.m. fluoride as sodium fluoride in drinking water. Mohamed \& Chandler (1982) suggested that fluoride 


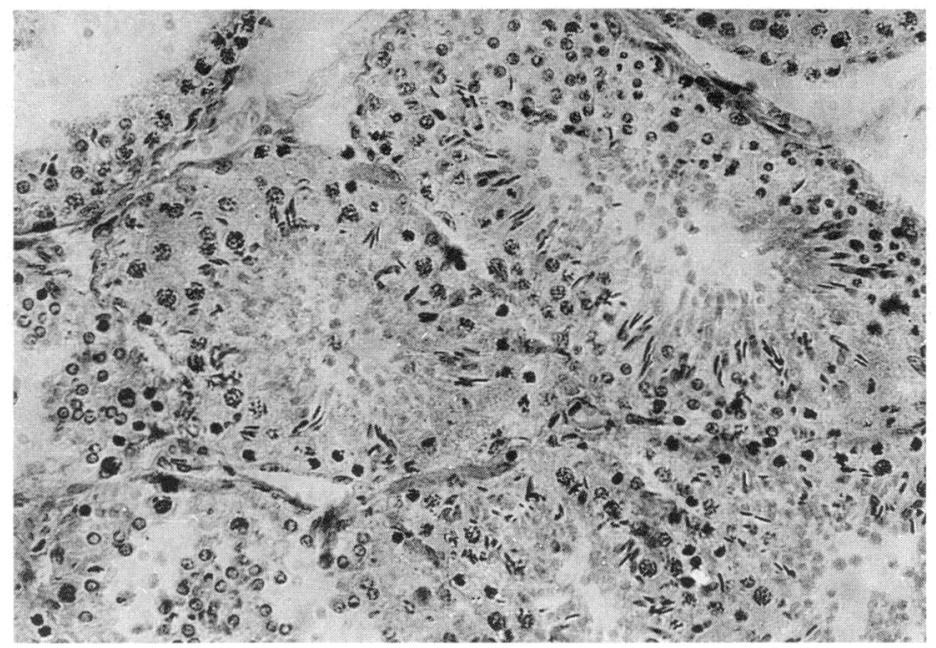

Fig. 1. Photomicrograph of a section of rabbit testis in the control experiment. showing cells in various stages of spermatogenesis. Note the clusters of spermatozoa: haematoxylin and eosin staining $(\times 250)$.

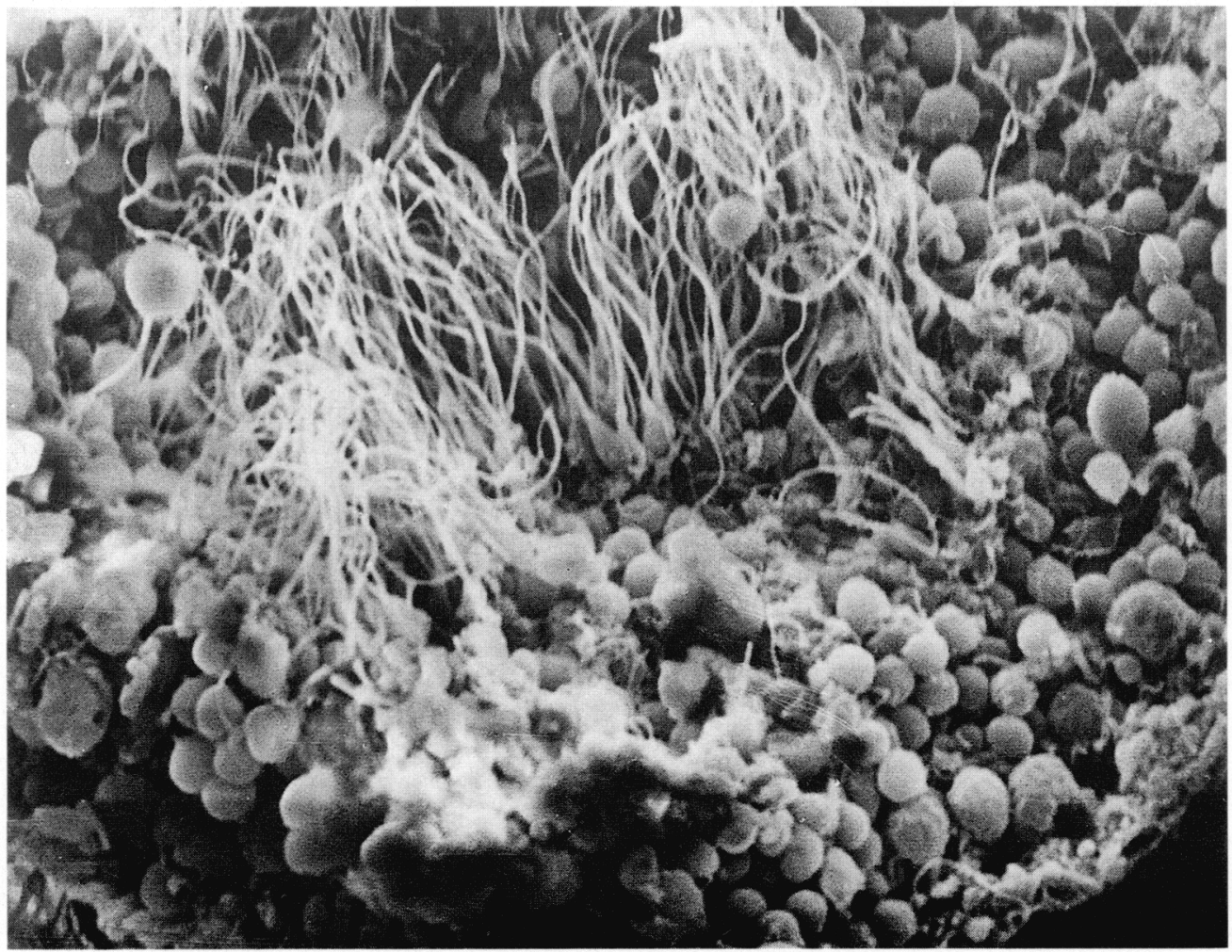

Fig. 2. Scanning electron micrograph showing spermatogenic cells and a large number of spermatozoa attached to the inner aspect of a seminiferous tubule of a control rabbit $(\times 900)$. 


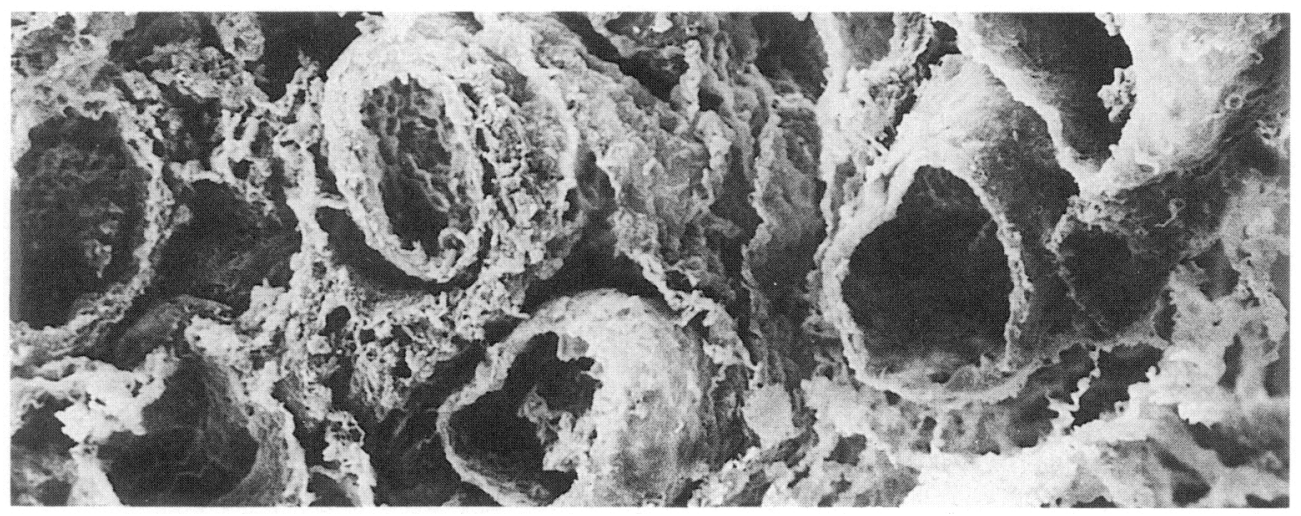

Fig. 3. Empty seminiferous tubules in testis of a rabbit treated with NaF for 29 months. seen under low magnification of scanning electron microseope $(\times 225)$.

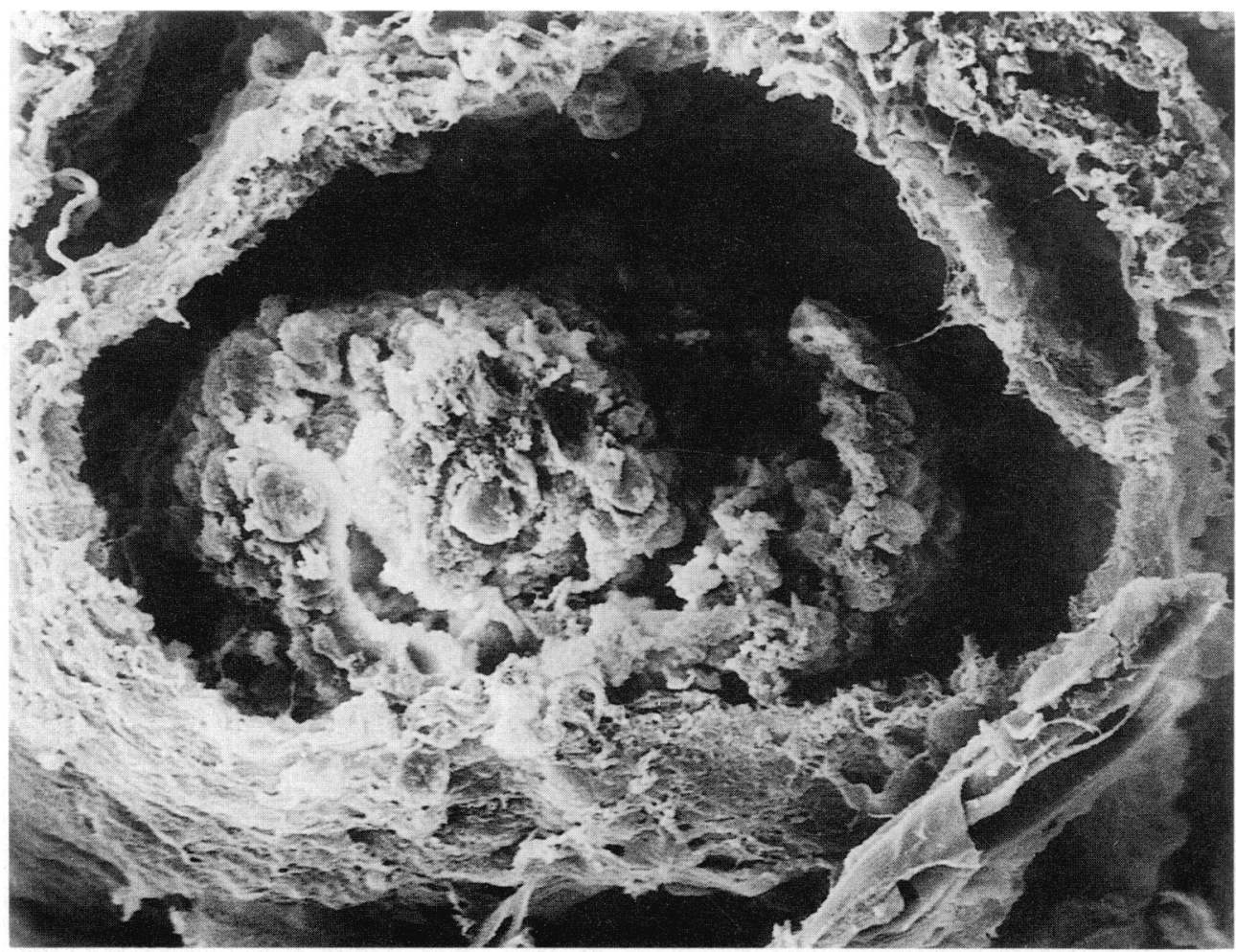

Fig. 4. Scanning electron micrograph showing a lump of degenerated spermatogenic cells in a seminiferous tubule of a rabbit treated with NaF for 29 months; note the absence of spermato7oa $(\times 900)$.

(as sodium fluoride) at 1200 p.p.m. in drinking water induces mitotic and meiotic chromosome aberations in mice. Ridha et al. (1978) noticed impaired spermatogenesis in mice given 125. 250 and 500 p.p.m. of lluoride in feed. Microscopic examination of testis structure in chickens by Mehdi et al. (1983) showed that 600 p.p.m. fluoride in feed impaired the initiation of spermatozoa. 


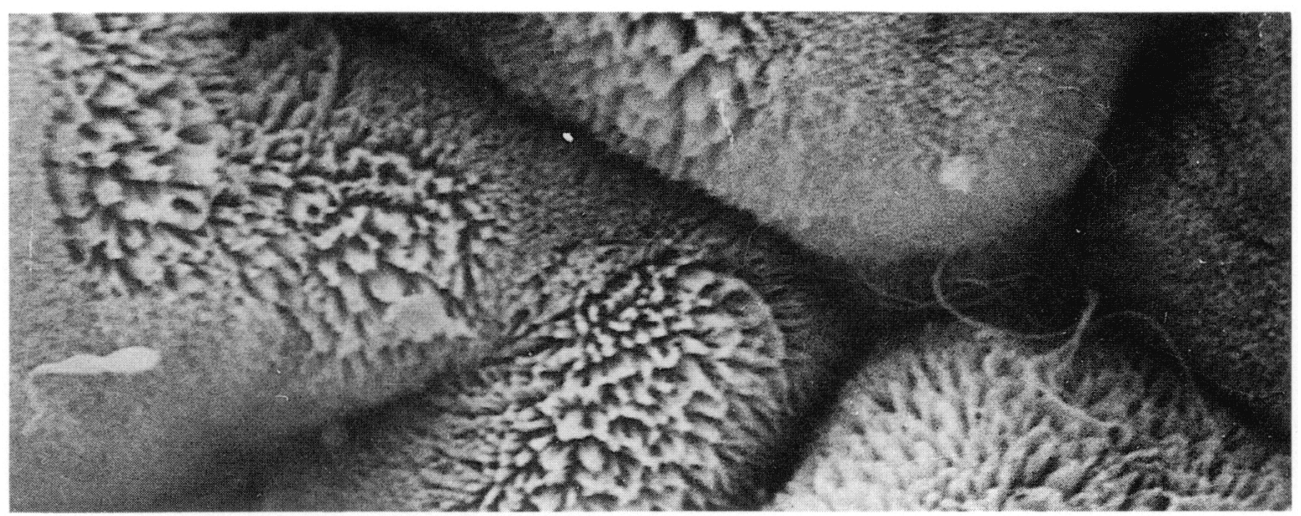

Fig. 5. Scanning electron micrograph of the epithelial lining of the lumen of the ductuli efferentes of the caput epididymidis of a control rabbit showing cilia on the epithelial cells. Some spermatozoa are seen amidst the cilia $(\times 900)$.

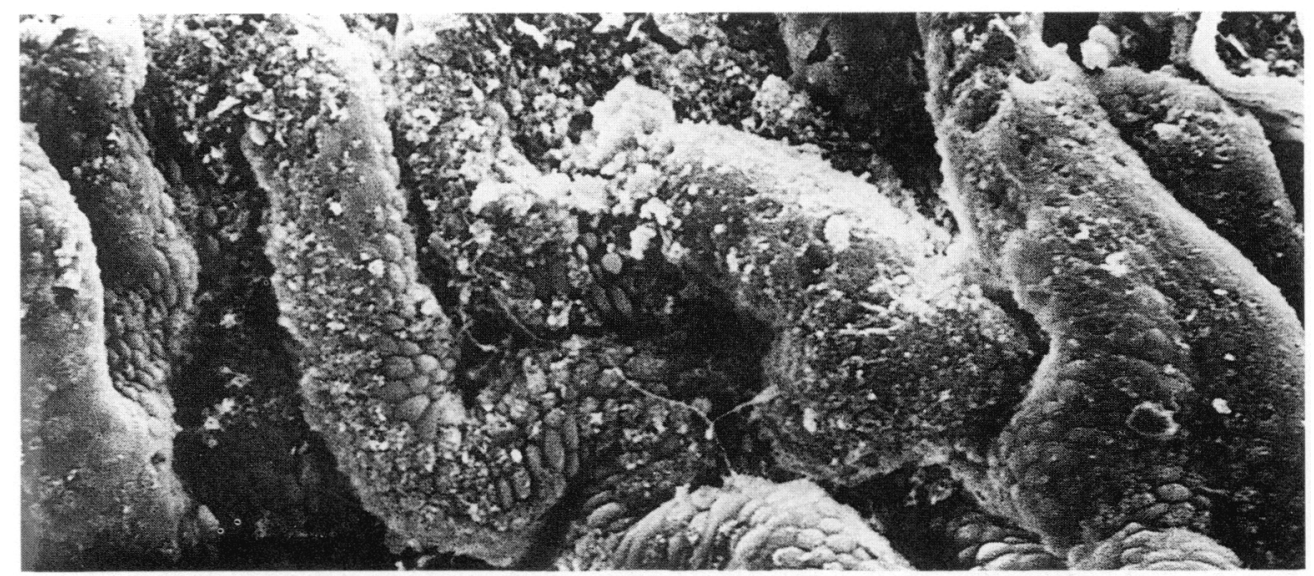

Fig. 6. Scanning electron micrograph of the epithelial lining of the lumen of the ductuli efferentes of the capul epididymidis of a rabbit treated with Naf for 18 months. Note the absence of cilia on the epithelial cells and that in some regions cell boundaries are not clearly visible and the cell surface appears to have been peeled off $(\times 450)$.

In India, fluorosis is endemic in several States; by drinking naturally fluorinated water with up to 38.5 p.p.m. fluoride, millions of people are affected with fluorosis. A recent report revealing infertility among married men in a highly endemic area in India (Neelam et al. 1987) led to an experimental study in rabbits. In the present study. the effects of fluoride on the rabbit male reproductive system were investigated. focusing on the structure of the testis, epididymis and vas deferens, using light and scanning electron microscopy.

\section{Materials and Methods}

Male rabbits weighing 14001800 g were housed individually in cages in the Central Animal Facility of the All India Institute of Medical Sciences. Fecding was ad lihitum with a standard animal dien (Hindustan Lever Limited, Bombay. India) and drinking water was provided from the public water supply, which contained $<0.5$ mg fluoride 1 . The animals were randomly assigned to two groups of 10 and kept under identical laboratory conditions. A solution of 


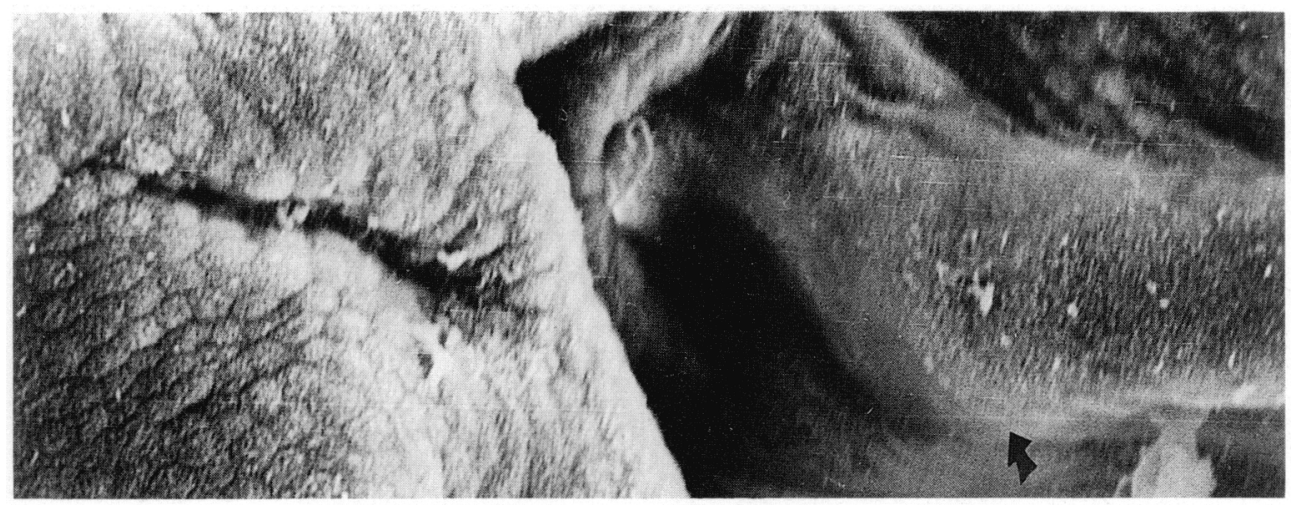

Fig. 7. Scanning electron micrograph showing epithelial cells with complete loss of stereocilia in the lumen of the vas deferens of a rabbit treated with $\mathrm{NaF}$ for 18 months. The arrow indicates a region where the cell outline is not clear, giving a smooth appearance to the luminal surface $(\times 1050)$.

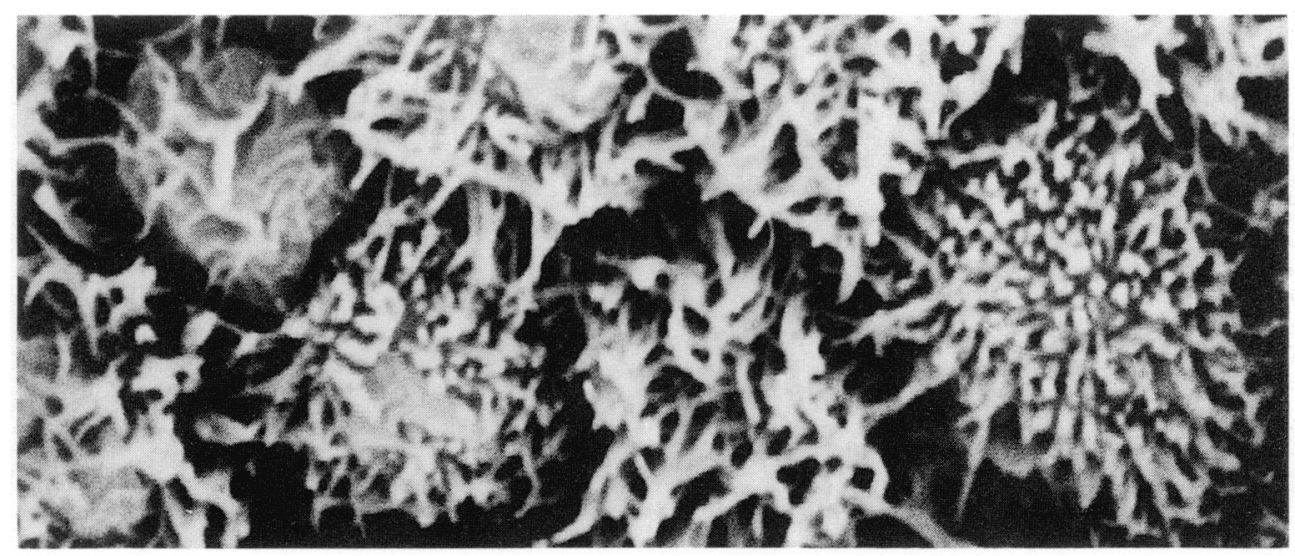

Fig. 8. Scanning electron micrograph of vas deferens of a control rabbit showing numerous stereocilia on the epithelial cells lining the lumen of the vas deferens $(\times 7000)$.

Nal in dejonized distilled water and at $10 \mathrm{mg}$ kg body weight was orally administered daily to one group of rabbits: the second group served as control. The rabbits were anaesthetized with ether and 7 were killed after 18 months of treatment and 3 after 29 months. The abdominal eavity was opened and testes, epididymis (caput) and vas deferens were dissected out and washed briefly in normal saline solution. The organs were cut into pieces and fixed in Bouin's tixative for $24 \mathrm{~h}$ for light microscopy. Some pieces of tissue, after washing in $0.1 \mathrm{~m}$ phosphate buffer, were fixed in Karnovsky`s fluid (Karnovsky, 1965) for 6 h for seanning electron microscopy.

Light microscopy. After fixation, the specimens were washed well, dehydrated through a graded series of alcohol. cleared in xylene and embedded in paraffin wax. Sections were cut at $5 \mu \mathrm{m}$ thickness and stained with haematoxylin and cosin.

Scanning electron microscop!: After fixation in Karnovsky's fixative, the specimens were washed in 0.1 m phosphate buffer and then fixed for $1 \mathrm{~h}$ in $0.5 \%$ osmium tetraoxide in the same buffer. After a few washes in $0 \cdot 1 \mathrm{M}$ phosphate buffer, the specimens were dehydrated through ascending grades of acetone. After critical-point drying followed by sputter coating with gold. the tissues were examined under a scanning electron microscope (Philips 501 B) operated at $15 \mathrm{kV}$. 


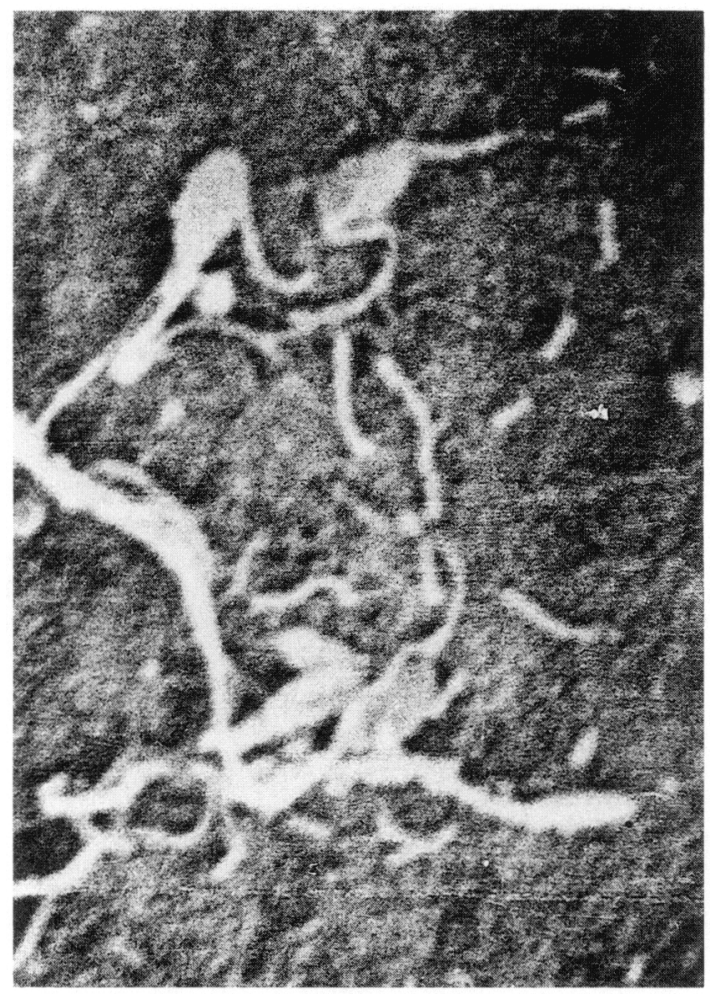

Fig. 9. Scanning electron micrograph showing fragments of spermatozoa in the lumen of the vas deferens of a rabbit treated with NaF for 18 months $(\times 1750)$.

\section{Results}

\section{Testes}

In animals treated for 18 months, different stages of spermatogenesis were clearly seen as in normal control animals (Fig. 1). Spermatozoa were in groups attached to the inner aspect of the lumen of the seminiferous tubules as in the control animals (Fig. 2), but in animals treated for 29 months complete cessation of spermatogenesis was observed and seminiferous tubules were devoid of spermatozoa (Fig. 3). Spermatogenic cells were disrupted and were seen as a lump in the seminiferous tubules under the scanning electron microscope (Fig. 4). Some spermatogenic cells were highly eosinophilic, with shrinking cytoplasm and some had deep-staining pycnotic nuclei denoting cell death.

\section{Epididymis}

In animals treated with $\mathrm{NaF}$ for 18 or 29 months, cilia on the epithelial cells lining the lumen of the ductuli efferentes of the caput epididymidis were less dense or absent in some regions, giving it a bald appearance compared with material from control animals (Figs 5 \& 6). At certain regions of the epithelial lining, the contour of the cells was not clear and appeared to be peeled off. In the caput epididymidis of animals treated for 18 months, there were fewer spermatozoa than in normal animals. 


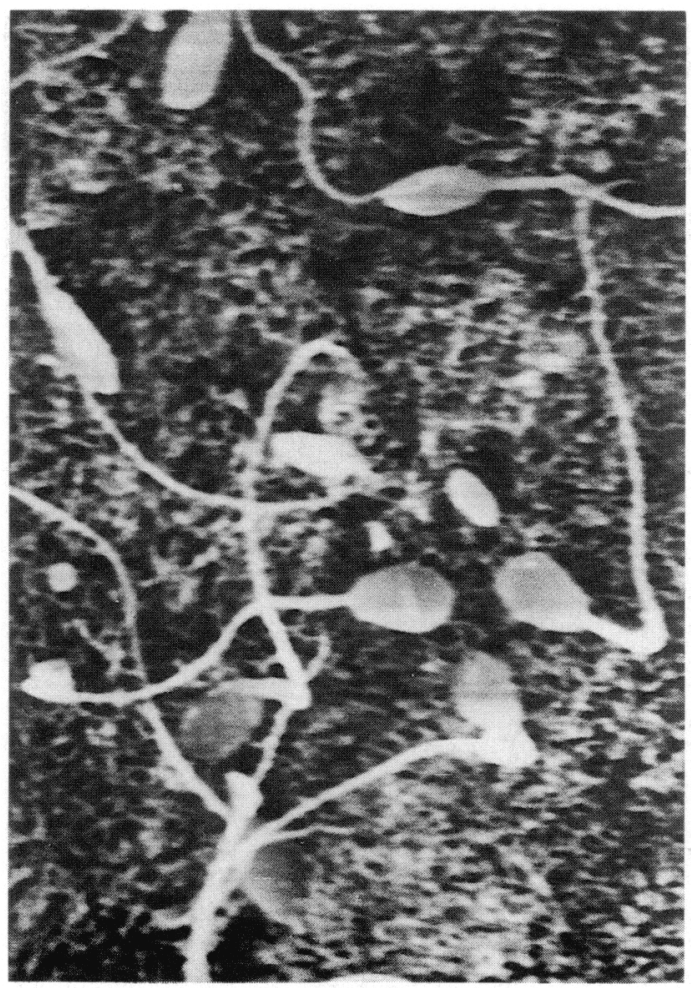

Fig. 10. Spermatozoa in the lumen of the vas deferens of a control rabbit $(\times 1750)$.

\section{Vas deferens}

In both the treated groups, stereocilia on the epithelial cells lining the lumen of the vas deferens were less dense or absent at some places, giving it a bald appearance (Fig. 7) in contrast to the dense layer of stereocilia in the controls (Fig. 8). Circular and longitudinal muscle layers appeared well developed in the treated animals as well as in controls, under the light microscope. There were fewer spermatozoa in the lumen of the vas deferens of animals treated for 18 months than in the controls. Under the scanning electron microscope, some spermatozoa with structural damage and fragments of spermatozoa were seen in the lumen of the duct of animals treated for 18 months but not in the controls (Figs $9 \& 10$ ). There was a significant reduction in the abundance of mucus droplets in treated animals.

\section{Discussion}

The present investigation demonstrated that oral administration of fluoride to rabbits for 29 months induces infertility; spermatogenesis ceased. It is evident that, in fluoride toxicity, testicular function is adversely affected. The lack of inhibition of spermatogenesis in animals treated for 18 months, may be because the blood-testis barrier prevents substances from deeper penetration into the seminiferous epithelium.

Skare et al. (1986) found that, in rats given $84 \mathrm{mg} \mathrm{NaF} / \mathrm{kg}$, plasma fluoride concentrations were as high as 12 p.p.m.. but testicular fluoride concentrations were, in most cases, only 10-20\% of plasma fluoride concentrations. A concentration gradient is maintained by the blood testis barrier. keeping fluoride concentrations lower in the testis than in the plasma. This permeability barrier 
may be passed during prolonged treatment with fluoride (e.g. for 29 months), but not in animals treated for 18 months, causing spermatogenic damage resulting in cessation of spermatogenesis.

The specific blood-testis barrier may be dependent on time, dose and species, and the mechanism by which fluoride passes through it needs to be investigated. In chickens, 150 and 300 p.p.m. of fluoride added to the feed did not impair spermatogenesis, but 600 p.p.m. impaired the initiation of spermatogenesis (Mehdi et al., 1983).

Significant changes observed in the epithelial cells lining the ductuli efferentes of the caput epididymidis and vas deferens of the treated animals suggest that fluoride induces mucosal damage. The abrasive nature of the gastric mucosa and the absence of mucus droplets on exposure to fluoride has been shown by Susheela \& Das (1988).

In the present study, although spermatogenesis appeared to be normal in animals treated for 18 months, there were fewer spermatozoa in the caput epididymidis and vas deferens than in the control animals, possibly because of the loss of cilia in the ductuli efferentes and the fragmentation of spermatozoa. The present study indicated that prolonged exposure to fluoride damages the male reproductive organs in rabbits, particularly the spermatogenic cells. The relevance and the implications of these observations for human subjects living in areas where fluorosis is endemic merits investigation.

We thank Mr S. C. P. Sharma of the Regional Electron Microscope Facility at the All India Institute of Medical Sciences, New Delhi for his excellent technical assistance. We also thank Mr B. Saha and Mr K. Mohandas for typing the manuscript. This work was supported in part by a postdoctoral fellowship to Dr Arbind Kumar under Technology Mission on Safe Drinking Water, Govt. of India.

\section{References}

Karnovsky, M.J. (1965) A formaldehyde gluteraldehyde fixative of high osmolality for use in electron microscopy. J. Cell Biol. 27, 137A.

Kaur, K. \& Singh, J. (1980) Histological finding of mice testes following fluoride ingestion. Fluoride 13, $160-162$.

Li, Y., Dunipace, A.J. \& Stookey, G.K. (1987) Effects of fiuoride on the mouse sperm morphology test. $J$. Dent. Res. 66, 15091511.

Mehdi, A.W.R., Al-Soudi, K.A., Al-Jiboori, N.A.J. \& Al-Hiti, M.K. (1983) Effect of high fluoride intake on chicken performance, ovulation, spermatogenesis and bone fluoride content. Fluoride 16, 37-43.

Messer, H.H., Armstrong, W.D. \& Singer, L. (1973) Influence of fluoride intake on reproduction in mice. J. Nutr. 103, 1319-1326.

Mohamed, A.H. \& Chandler, M.E. (1982) Cytological effects of sodium fluoride on mice. Fluoride 15, 110118.

Mukherjee, R.N. \& Sobels, F.H. (1968) The effects of sodium fluoride and iodoacetamide on mutation induction by $\mathrm{X}$-irradiation in mature spermatozoa of Drosophila. Mutat. Res. 6, 217-225.

Neelam, K., Suhasini, R.V. \& Sudhakar, R.Y. (1987) Incidence on prevalence of infertility among married male members of endemic fluorosis district of Andhra Pradesh. In Proceedings of a Conference of the International Society for Fluoride Research, Switzerland (Nyon) (Abstract).
Ridha, M., Al-Jiboori, N. \& Mehdi, A.W. (1978) Effect of high fluoride intake on reproductive system of the male mice. Iraqi J. Vet. Med. 2, 103-135.

Schulz, J.A. \& Lamb, A.R. (1925) The effect of fluorine as sodium fluoride on growth and reproduction of albino rats. Science, N.Y. 61, 93-94.

Skare, J.A., Schrotel, K.R. \& Nixon, G.A. (1986) Lack of DNA-strand breaks in rat testicular cells after in vivo treatment with sodium fluoride. Mutat. Res. 170,8592 .

Susheela, A.K. \& Das, T.K. (1988) Chronic fluoride toxicity: A scanning electron microscopic study of duodena! mucosa. J. Toxicol. Clin. Toxicol. 26, $467-476$

Tokar, V.I. \& Savchenko, O.N. (1977) The influence of inorganic fluorine compounds on functional condition of the hypophysis-testes system. Probl. Endocr. (Mosk) 23, 104-107.

Udall, D.H. \& Kellers, K.P. (1952) A report on fluorosis in cattle in Columbia River Valley. Cornell Vet. 42, 159184.

Vogel, E. (1973) Strong antimutagenic effects of fluoride on mutation induction by trenimon and 1-phenyl-3, 3-dimethyltriazene in Drosphila melanogaster. Mutat. Res. 20, 339-352. 